\title{
Prototyping: A Politics of Memory
}

\section{SIGRADI2018 TECHNOPOLITICAS \\ xxii congresso da sociedade iberoamericana de gráfica digital 22th conference of the iberoamerican society of digital graphics 07|08|09|novembro|2018 iau usp | são carlos $\mid$ sp br}

\author{
Hugo Mulder \\ IT University of Copenhagen | Denmark | hugo.mulder@gmail.com
}

\begin{abstract}
This paper presents a view on the architectural prototype as an exteriorisation of human memory. Bernard Stiegler describes the politics of memory involved in the process of hypomnesis, in which memory is stored in technology. Stiegler's ideas with relation to the prototype were developed while working on a research prototype. Four modes of exteriorisation have been extracted from that process: the use of memory aids, the prototype as stepping stone for thought, the digitisation of fabrication, and the prototype used for communication. This analysis provides a pathway for making expert knowledge available and accessible as a common good.
\end{abstract}

Keywords: Prototype; Exteriorisation; Memory; Hypomnesic milieu.

\section{INTRODUCTION}

One of the recurring issues of knowledge generation and application is the isolation of knowledge in disciplinary silos (Jacobs, 2014; Nowotny, 2004; Stirling, 2014). A tension exists between forces that incentivise monodisciplinary research, and others that seek to bring integrative multi-disciplinary solutions. The built environment as the product of design, has a rich history of productive collaborative and interdisciplinary efforts. But it is in no way exempt from the challenges of bringing together deep expertise from different areas, especially with the integration of new disciplines, such as those in information technology, that become dominant in the design and operation of buildings and infrastructure.

An influential effort to bring together expertise in the design of the built environment is the use of digital collaborative systems, predominantly referred to as building information models (BIM). As useful and beneficial as these models may be for the design and building process, the systems involved are expert systems-even the operation of the BIM systems has become a new expertise in itself (Barison \& Santos, 2011; Davies, Wilkinson, \& McMeel, 2017). So how could the expert knowledge contained in the design become otherwise part of the common good that is called for by this conference?

Along with the development of BIM, digitally controlled modes of fabrication have reduced the procedural distance between drawing (or 3D modelling) and making. This effectively brings together more closely the expertise of design and that of fabrication. One of the benefits is that designers may receive haptic feedback relatively early in the design process that could inform their design. Especially for building designers-that have traditionally seen a strict separation between the process of design and that of construction-this narrowing of the gap is significant. Another benefit is the reduced effort for building designers to engage in an active practice of prototyping, leading to more-and more complexphysical artefacts as part of the design process.

In a series of fifty interviews with architects and building engineers, Jane Burry and Mark Burry have sought to clarify the multiple roles of the prototype in architectural and engineering practice (M. Burry \& Burry, 2016). In response to the opening question "What is a prototype?", they received fifty different answers, which nevertheless led them to adopt a number of loose groupings. One of those groups is identified as the prototype as a tool for thinking. Jordi Truco and Sylvia Felipe from HYBRIDa in Barcelona explain it as follows: "Unless you understand prototyping as a process in which ideas and making inform one another, [...] you will see only a product, not the opportunity to experiment and create something new" (p. 64). Prototyping is positioned not just as an informed process of making, but as a process of thinking taking place through the act of making.

This paper develops the idea of the prototype as a tool for thinking by applying philosophical ideas of French philosopher Bernard Stiegler. One of Stiegler's claims is that human memory has been exteriorised in technology since the emergence of the genus Homo, with the precursors of the modern human (Stiegler, 2010). Since then, he writes, technological and human development have evolved together, giving rise to an extra layer of memory: next to genetic memory of the species and individual memory of the organism, technology constitutes a third layer of memory. But where the offloading of memory to technology unquestioningly enhances certain cognitive capabilities, it will at the same time reduce the innate abilities for memorising and recollection. This is why Stiegler refers to this process as a politics of memory.

The interpretation of Stiegler's ideas with regards to the prototyping process, has been developed while working on a specific research prototype. This paper does not concern the specifics of that prototype or the larger 
research context that it is part of. But it will at times refer to specific features of the prototype in order to describe the process. The research prototype speculates about architectural space that is defined by movement and consists of eight transparent arches (Figure 1). The arches are formed of strips, that can be kinetically bent and twisted by rotating their two bases. For that purpose, a total of 16 motorised turntables have been installed. The process of design and making, as well as the prototype itself form the basis of the reflective analysis that led to the insights presented in this paper. These insights show how expert knowledge embodied in the prototype can become available as rich multi-layered understanding around a central starting point.

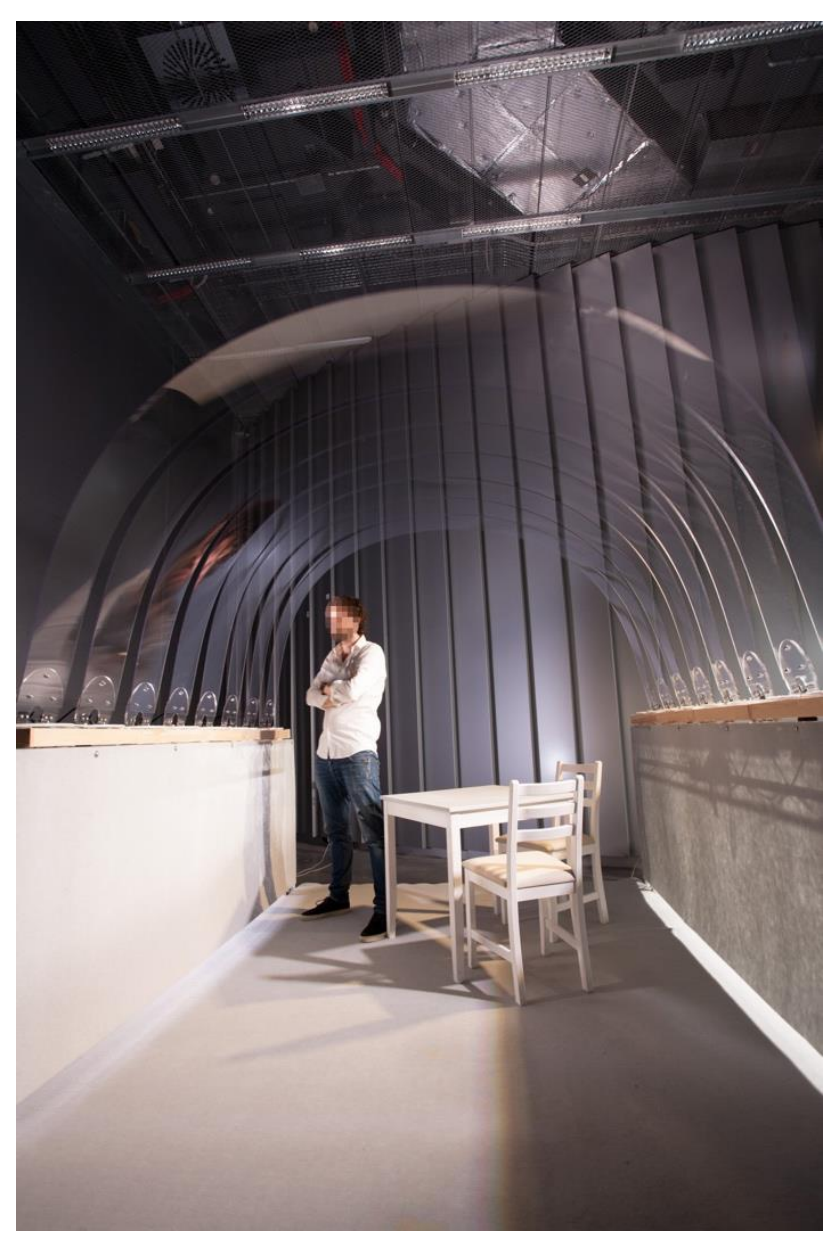

Figure 1: Research Prototype. Source: Author.

\section{METHODOLOGY}

Jonathan Hill writes that architectural design is a mix of using drawing to represent ideas, of developing provisional ideas to be subjected to experience, of functional problem solving, and of design and making (Hill, 2013). The explorative practice of architecture, Hill suggests, is performed as a triptych: "Studying the history of architecture since the Italian Renaissance, it is evident that researching, testing and questioning the limits of architecture occur through drawing and writing as well as building" (p. 19).

The paper's argument is supported by a research process that can be characterised as research by design, employing design thinking in explorative theory building. To implement this trajectory, a research prototype was developed for a speculative kinetic architectural installation. The complex mechanical parts of the prototype were parametrically designed, integrated in a digital prototype, and fabricated using a CNC process. As part of a larger research project, the prototyping process ran alongside scholarly processes of critical literature review and descriptive analysis of reference works, in order for these three strands to inform each other.

The considerations and practical processes described in this paper, concern a type of installation that is referred to as a research prototype, by which is meant a prototype for research. This prototype guides and challenges the research by providing ground for critical reflection. The process central to this paper therefore is a prototyping process. The prototyping in this research involves design and making, two subprocesses that have proven to be difficult to separate. In the first place because design and making were conducted by the same person, causing feedback cycles to be short and direct, and in the second place because they both relied on digital processes that enabled drawing and making to be similar activities. In prototyping here, making is absorbed in the design process, rendering prototyping a particular form of doing design.

As prototyping is conducted in service of research, we could speak of research by prototyping, a special case of research by design. Christopher Frayling has referred to this research practice as research through design, asserting that the practice of design in itself is providing the methods to conduct research (Frayling, 1993). Although in some places this form of research has been practiced for many years and a deep understanding has been built around it, over the last years it has more broadly received renewed attention, especially in disciplines where design is the primary practicearchitecture included. Frayling, who was at the RCA when he wrote his seminal text, discussed both art and design, explaining that the process of research through these practices acts as a similar mechanism with similar concerns.

As Frayling has set out, the goal of research through design is the insight that is gained from doing design, rather than the actual design outcome. This would imply that the design and making of an artefact in a prototyping process (and not directly the artefact itself) are the key concerns of the research practice. In the prototyping process however, the role of the artefact is multifaceted. In an essay about the role of the artefact in artistic research, Linda Candy and Ernest Edmonds write: "The artefacts that practitioners create are an integral part of practice whether or not there is a formal research process" (Candy \& Edmonds, 2010, p. 123). Even though Candy and Edmunds, like Frayling, emphasise the process of design and making in their writing, they affirm the inseparability of artefact and process. The prototype as artefact holds significance also beyond enabling the process of its becoming. In the analysis that this paper presents, special attention is paid to that aspect by regarding the prototype as the embodiment of exteriorised cognition.

Positioning this research in the tradition of research by design is helpful because an increasing body of academic work is lending credibility to this approach (De Walsche \& 
Komossa, 2016; Fraser, 2013; Joost, Bredies, Christensen, Conradi, \& Unteidig, 2016; Moloney, Smitheram, \& Twose, 2015). But that same body of work is all but univocal about how such research is undertaken. The author's background as design engineer is only partially helpful. It means for example that the author has gained skills for practicing design, but not for being reflective on it. Author's experience has covered projects along a range of feasibility, but always with an intent for realisation. From that experience, design, especially early stage design, has often taken an intuitive path of trying solutions until they seemed right. This intuitive process of trying solutions based on tacit knowledge and judgement preceded a reflective process of critical writing where theory and process were shown to interrelate.

\section{RESULTS}

The prototype in this section is presented as a tool for thinking that couples the world of ideas and the world of physical making. Prototyping is first explained as a process of technologically exteriorised thought, especially along the lines of Bernard Stiegler's thesis of memory. A breakdown will then take place of prototyping into four aspects: memory aids, stepping stone, digitisation of fabrication, and communication.

\section{THINKING BY PROTOTYPING}

The understanding of ideas and making as dynamically informing each other was laid out by Michael Speaks in a series of articles and interviews in 2002 and 2003 (Speaks, 2002b; 2002a). Speaks writes about design intelligence as emerging from a new way of doing architecture that he observed in several young architecture firms at that time.

Such design intelligence is explained as an opportune collating of information that cannot all be known to be true, but that collectively becomes a transformative force for innovation. In historical perspective, Speaks argues, such intelligence replaces the more encompassing views that were present in theory, and philosophy before that. In his writing, Speaks emphasises the role of the prototype, not as a representation of the design objective, but rather as a form of production that drives change. "[T]he search for prototypes that solve specific problems has today been replaced by prototypes, scenarios, versions and spreadsheets that are instead used to innovate. The product is not so much the prototype as it is the innovations that occur as a result of thinking with and through the prototype" (Speaks, 2002b, p. 6). The architecture firms that he refers to, "also view design as dynamical and nonlinear and not as a process with a beginning, middle and end. Accordingly, the relationship between thinking and doing becomes more and more blurred so that thinking becomes doing and doing becomes thinking" (b, p. 6).

When thinking becomes doing and doing becomes thinking, we could think of that as a shift rather than inversion. Thinking becomes doing suggests that thinking becomes an active process, in the context of what Speaks writes, perhaps a process that involves the hands (or other body parts) in making something. When doing becomes thinking, we can understand that active process as constitutive of thinking. The active process of doing becomes the primary process through which we think.
So far, the process of making has been addressed as a process of thinking. But where does that leave the artefact? Philosopher of mind Alva Noë gives us a clue as to how to address the physical construct in a recent publication that addresses the use of technologies and the profound influence they exert on us. He writes: "Technologies organize our lives in ways that make it impossible to conceive of our lives in their absence; they make us what we are" (Noë, 2015). He goes on to unpack the technology of writing, of representing language in symbols. Noë suggests that writing is not just a form of communication, but that it organises thought: "Writing [...] is a technique for thinking about whatever domain it is we are writing about" and that "notations make it possible to frame problems and think about phenomena in a way that we couldn't do without notation" (Noë, 2015, p. 40). Writing in this sense is thus a technique that is external to us, and at the same time elemental to how we think.

A similar argument is made by Youn-Kyung Lim, Erik Stolterman and Josh Tenenberg in a paper about prototyping in the context of human-computer interaction (HCl) (Lim, Stolterman, \& Tenenberg, 2008). Their discussion leads them to characterise prototypes as both filters and manifestations of design ideas. As filters, prototypes allow designers to test the design, without engaging necessarily with the full context and the complexity of all the detail. A prototype can be brought back to just the essential parameters to make particular design decisions, leaving out what seems irrelevant. As manifestations, prototypes are externalisations of design ideas. Lim et al. refer to the thesis of the extended mind, a view of cognition that gives prominence to external context as constitutive of our cognitive functions. Andy Clark and David Chalmers, as original proponents of this view, explain that:

the human organism is linked with an external entity in a two-way interaction, creating a coupled system that can be seen as a cognitive system in its own right. All the components in the system play an active causal role, and they jointly govern behaviour in the same sort of way that cognition usually does. If we remove the external component the system's behavioural competence will drop, just as it would if we removed part of its brain. Our thesis is that this sort of coupled process counts equally well as a cognitive process, whether or not it is wholly in the head. (Clark \& Chalmers, 1998, pp. 8-9)

Just like writing, when we engage in prototyping, we establish a coupled system. We engage in a process that includes elements external to us, but that nevertheless form part of our cognitive processes. The writings of French philosopher Bernard Stiegler provide a contemporary philosophical perspective on this external coupling. Like Noë, Stiegler makes a claim about the exteriorisation that takes place in writing and extends that to technology more widely. Stiegler uses the term hypomnesis to refer to the process of offloading memory to technology. When, like in writing, such a technology allows simultaneously for a coding and a decoding of memory (knowing how to write implies knowing how to read), Stiegler refers to this as associated hypomnesis. Prototyping in this paper is positioned as a process of associated hypomnesis. To be literate at prototyping is like reading and writing: a technique to structure thinking in a particular way.
3 


\section{MEMORY AIDS AND LITERAL ANNOTATION}

The first of the identified hypomnesic modes in the prototyping process is the use of simple memory aids. Hypomnesis is induced by placing items, such as screws, nuts and bolts at meaningful locations, such as those places where they should be installed. Before they perform their primary function, these items act as memory aid, to help the installer remember where work needs to be done. And sometimes a tool, such as a tape measure or a screwdriver, acts as memory aid, for example when it is placed somewhere to remember a particular task or sequence. Repetition was an important reason for using memory aids. Because the eight strips and their rotating bases are identical, it was easy to forget which strip a particular task should apply to. The two strips on each side were easy to identify based on them being edges and adjacent to edges, but the four strips in the middle would be easily confused without some sort of marker. And for the assembly of the turntables, which was repeated 16 times, all the components were laid out for assembly in order to avoid forgetting parts in the process. Memory aids as described here, had a function during the process of prototyping, but lost their function as a memory aid after being installed. More permanent aids can be found in the colour coding of the port and starboard controllers, that have red and green mounting plates and wire markers.

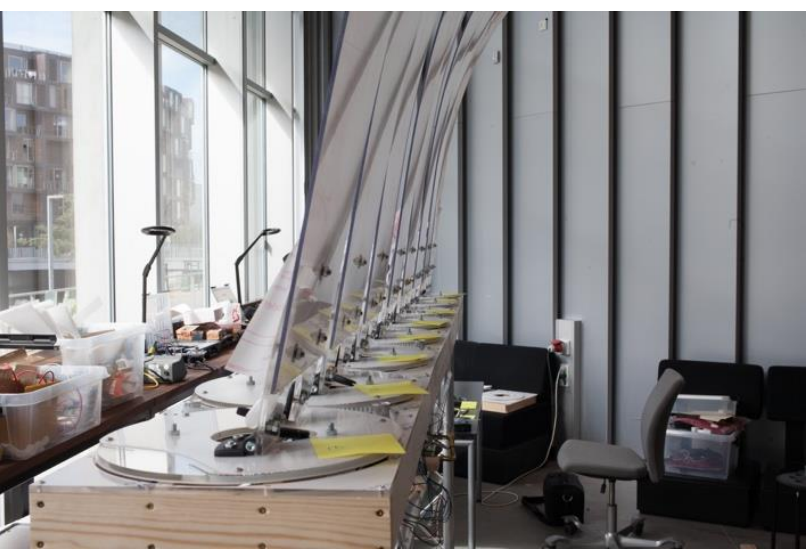

Figure 2: Notes on artefact aiding controller calibration. Source: Author.

In line with this, is the use of literal annotations, which involves writing comments on the artefacts, situated where they apply. This is an aspect that also mainly applies to the production process of prototyping. In the basis, it is nothing other than writing, but the writing is being given additional meaning by a context. Annotations can therefore often be brief, because the lack of direct meaning is complemented by the context it is found in. A number written on a component could for example refer to a dimension, to the number of holes to be drilled, or to orientation. This technique has mainly been used in my process by writing with a marker on the protective plastic film that covered the transparent materials and on Post-its on other materials to avoid leaving a permanent trace of the comments after they had served their purpose. Literal annotation is common practice for construction workers that annotate raw construction materials. Such scribbles sometimes remain visible on untreated surfaces of buildings.

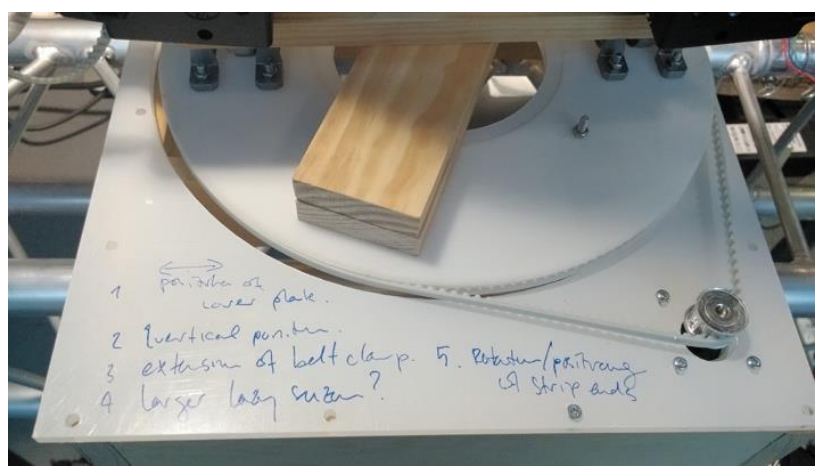

Figure 3: Literal annotations on physical artefact. Source: Author.

Like memory aids, the annotations appeal to other, living memories in order to be useful. They are part of a more complex thought process, which can be highly individual. Not everyone would interpret a scribble in the same way, or understand a memory aid as something actionable. But it is not difficult to see how such aids can become part of a shared practice, forming a language in itself that allows for some form of communication and task sharing between multiple prototypers.

\section{STEPPING STONE}

The second mode in which the prototype supports thinking, is as a stepping stone for thought. This applies to the process of prototyping itself, as well as to the larger context that the prototyping takes place in. Within the prototyping process, in a linear manner, this means that making one thing, leads to the next. A produced artefact, such as a holding plate that connects a strip to its base, will give feedback about its performance. Making it too long may lead to a holding plate that provides too much stiffness to the strip. Making it too short may cause the strip to buckle through a lack of support. In contemporary engineering practice, such feedback would often be derived from computational simulation, where similarly the outcome would be a stepping stone in an iterative process. And more generally in the design process, the drawing might perform such a function in a developing process. A specific example is a series of six drawings by Peter Cook, called the Veg House, where the aim of the drawings is to evolve. He writes:

For me, there is the delightful experience of carrying out a process that can enhance the primary decisions (of size, position, figure or direction), with such a mobile and extensive addition of evidence. It is as if the first part of the illustration is being illustrated by the second. (Cook, 2014, p. 172)

The drawing allows for the construction of something that cannot simply be thought. It needs to be drawn in order to draw the next part. Stiegler also discusses the drawing, by referring to the dialogue between Socrates and Meno, as told by Plato. In the dialogue, Socrates summons a slave and questions him about geometry, drawing a diagram in the process:

The drawing, as hypomnesic memory, is therefore indispensable to this potential philosopher, the slave boy, and to his passage into action, that is, his anamnesis. It constitutes a crutch for understanding, a space of intuition entirely produced by the gestures of the slave tracing in 
the sand the figured effects of this reasoning. The sand holds "in view" the results of the slave's intuition and understanding; it thus facilitates the extension and construction of the geometrical proof. (Stiegler, 2010, p. 74)

The drawing therefore, and by extension the 3D digital model, but also the physical prototype, lets us keep in view a certain understanding. Beyond being a series of stepping stones, each leading to the next thought, the prototype is the construction of a thesis with a complexity that can only be developed through such a structured externalisation.

\section{DIGITISATION OF FABRICATION}

The third aspect of externalisation is the digitisation of fabrication. Not just in the form of the tool as a prosthetic that is the 3D-printer, or the laser cutter, or the CNCrouter, but by taking away a mental step between drawing and making. Stiegler writes about driving a car:

[T] he more the automobile is improved, the less we know how to drive. Eventually, the GPS driving assistant will replace the driver altogether; we will lose control over our own sensory-motor schema as such guidance becomes automatic, a formal element of the navigation system. (Stiegler, 2010, p. 68)

The digital fabrication tools at this point still require a significant amount of know-how to operate well. Although their reach has increased well beyond a small group of expert users, they have arguably not yet lived up to the promise of bringing these technologies to the masses. This may change with time, taking away what is left to know about materials and to understand of the process. For the users of digital fabrication tools, the direct link between a digital drawing and the production of an artefact has already removed the necessity to master a manufacturing skill. The precision of most of these tools out-does most humans, so it is not only removing the control of the sensory-motor schema as Stiegler writes, but it removes the incentive to learn that control in the first place. Digital fabrication in this sense is both an enabler and a threat, a pharmakon as Stiegler refers to it, that enables humans to reach further, but at the same time takes away an innate capacity. Stiegler writes about this as a grammatization of gestures. Grammatization, he explains, following Derrida, is the discretisation of the continuities that shape our lives. "Writing, as the breaking into discrete elements of the flux of speech [...], is an example of a stage in the process of grammatization" ( $p$. 70). In the industrial age, he writes, know-how was transferred to gesture-reproducing machines, without an understanding of the workings of these machines. What makes digital fabrication in our current time different, is the culture that surrounds it of self-taught expertise. 3D printers can be partially 3D printed following online instructions. The workings of a laser cutter are easily found online and red-up on. Thereby, they do not just reproduce the same pre-programmed gestures, but they produce the gestures that they are instructed to by the user. The consumer is also the producer.

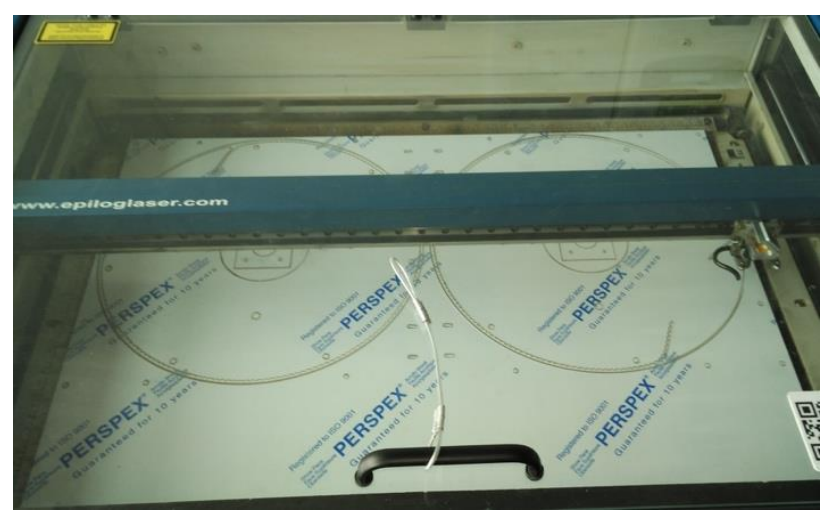

Figure 4: Laser cutting of turntable top plates. Source: Author.

Stiegler describes this time as the "era of digital networked hypomnemata [that] inaugurates the industrial hypomnesic milieu" (Stiegler, 2010, p. 83). The digital fabrication technologies (but not just those) are in part powered by the Internet, providing easy access to information, training material and examples. Even access to existing machines is not a requirement, because many of the machines can in some form be self-built following detailed examples. Lively online communities of programmers and makers further ensure that those in need of help get the support they need to continue. We can understand Mark Goulthorpe's words as particularly applicable for this type of Internet enabled prototyping: "[p]rototyping ensures that, to some degree, invention displaces reliance on expertise-in other words, that there is a different set of drivers behind cultural production beyond the emulation of prior excellence" (M. Burry \& Burry, 2016, p. 78).

\section{COMMUNICATION}

The fourth aspect of externalisation lies in the communication enabled by the prototype. Through its physical manifestation, the prototype is a particular expression of thought, laid out by the prototyper and available for interpretation by anyone who attends to it. This interpretation may take place on different levels, depending on the personal history of the interpreter. It may, to some, just be a visual object with a certain form and behaviour, like the alphabet would be for the illiterate. For others, who are more versed in its language, it may evoke associations linked to a professional field or practice. We might think of it however as less restrictive than a natural or a formal language, allowing for multiple and diverging interpretations. In being a starting point, and not a conclusion, the prototype therefore becomes an enabler of communication across fields, and as we will see, across disciplines in academia and industry. The existence of multiple interpretations may have been cause for confusion, were the prototype to illustrate a particular phenomenon. But it is not; the prototype has been an instrument to develop lines of thought, and its multiple understandings make it richer for it.

This understanding of the prototype as communicating through different layers of understanding is illustrated by a spin-off project that was directly inspired by the prototype-a collaboration between Arup and the glass industry (reference withheld). The spin-off project started as a conversation about the prototype when it was in an early development stage, and the use of thin glass as 
material for the transparent strips was suggested. Thin glass is used predominantly in electronic hand-held devices. Apart from considering the material in the context of the prototype, it was recognised that certain glass manufacturers were looking for opportunities to use thin glass in the building context. The prototype thus gave rise to an understanding in a commercial context for a new product application. And rather than the speculative prototype that it set out to be, another new understanding of the prototype as a demonstrator of adaptive facade behaviour emerged. Not just was the prototype allowing for these interpretations, it allowed back and forth, the communication of very different concerns. The physical prototype was a placeholder, a common starting point for discussion.

\section{DISCUSSION}

This paper promotes a particular framing of technology as memory politics and applies that framing to the practice of physical prototyping. As a result, an understanding of the process of prototyping and also of the prototype itself emerges as an exteriorisation of thought.

The insights in this paper result from a reflection on the prototyping process as research by design that was conducted in a larger research project. This reflection takes into account not just the process of prototyping, but ascribes a particular significance to the artefact as well.

The exteriorisation is broken down in four aspects affecting individual, subjective processes of memory storage and retrieval, and collective processes of knowledge transfer and communication. The aspects are described as memory aids, stepping stones for thought, digitisation of fabrication, and communication.

A spin-off project that took the prototype from an academic analytic tool to a commercial and practical context, was used to illustrate how the process of exteriorisation has led to a shared understanding across disciplinary bounds and across the academic-industry border. We may therefore interpret the exteriorisation of thought in the prototype as a contribution to the making available of knowledge with an inherent potential to transcend the immediate context of its conception.

\section{ACKNOWLEDGMENTS}

This research has in part been financially sponsored by Arup. The spin-off project has been in collaboration with Arup and was funded separately by a grant from Invest in Arup. It would not have been possible however without the efforts of several Arup colleagues and the generous investment of their time.

\section{REFERENCES}

Barison, M. B., \& Santos, E. T. (2011). The Competencies of BIM Specialists: A Comparative Analysis of the Literature Review and Job Ad Descriptions. In Computing in Civil Engineering (2011). http://doi.org/10.1061/41182(416)73
Burry, M., \& Burry, J. (2016). Prototyping for Architects. Thames \& Hudson Limited.

Candy, L., \& Edmonds, E. (2010). The Role of the Artefact and Frameworks for

Practice-based Research. In M. Biggs \& H. Karlsson (Eds.), The Routledge Companion To Research In The Arts (pp. 120137). Routledge.

Clark, A., \& Chalmers, D. (1998). The extended mind. Analysis, 7-19.

Cook, P. (2014). Drawing: The Motive Force of Architecture. Chichester, UK: Wiley. http://doi.org/10.1002/9781118827543

Davies, K., Wilkinson, S., \& McMeel, D. (2017). A review of specialist role definitions in BIM guides and standards. Journal of Information Technology in Construction (ITcon), 22(10), 185-203.

De Walsche, J., \& Komossa, S. (Eds.). (2016). Prototypes and paradigms: Architectural research vis-à-vis research-bydesign. TU Delft Open.

Fraser, M. (Ed.). (2013). Design Research in Architecture: An Overview. Ashgate Publishing, Ltd.

Frayling, C. (1993). Research in Art and Design. Royal College of Art Research Papers, 1(1).

Hill, J. (2013). Design Research: The First 500 Years. In M. Fraser (Ed.), Design Research in Architecture: An Overview (pp. 15-34). Ashgate Publishing, Ltd.

Jacobs, J. A. (2014). In Defense of Disciplines: Interdisciplinarity and Specialization in the Research University. University Of Chicago Press.

Joost, G., Bredies, K., Christensen, M., Conradi, F., \& Unteidig, A. (Eds.). (2016). Design as Research: Positions, Arguments, Perspectives. Birkhäuser.

Lim, Y.-K., Stolterman, E., \& Tenenberg, J. (2008). The anatomy of prototypes: Prototypes as filters, prototypes as manifestations of design ideas. ACM Trans. Comput.-Hum. Interact., $15(2), \quad 7-27$. http://doi.org/10.1145/1375761.1375762

Moloney, J., Smitheram, J., \& Twose, S. (Eds.). (2015). Perspectives on Architectural Design Research: What Matters - Who Cares - How. Spurbuchverlag.

Noë, A. (2015). Strange Tools: Art and Human Nature. Farrar, Straus and Giroux.

Nowotny, H. (2004). The Potential of Transdisciplinarity. In H. Dunin-Woyseth \& L. M. Nielsen (Eds.), Discussing Transdisciplinarity: Making Professions and the New Mode of Knowledge Production, the Nordic Reader, Oslo School of Architecture, Oslo, Norway. (pp. 10-19).

Speaks, M. (2002a). Design intelligence part 1: introduction. $A+U$ (Architecture and Urbanism), (387), 10-18.

Speaks, M. (2002b). Design intelligence: or thinking after the end of metaphysics. Architectural Design, 72(5), 4-6.

Stiegler, B. (2010). Memory. In Critical terms for media studies (pp. 64-87). University of Chicago Press.

Stirling, A. (2014, June 11). Disciplinary Dilemma: Working Across Research Silos is Harder Than It Looks. The Guardian. Retrieved from https://www.theguardian.com/science/politicalscience/2014/jun/11/science-policy-research-silosinterdisciplinarity 